\title{
O RITUAL DE LIBERTAÇÃO E CURA IURDIANO SEGUNDO A PERSPECTIVA DE MIKHAIL BAKHTIN
}

\author{
Mauro Meirelles
}

\section{INTRODUÇÃO}

Com base na leitura do texto de Jaçanã Ribeiro intitulado "O simulacro da alteridade: uma análise discursiva do ritual de exorcismo da Igreja Universal do Reino de Deus", buscamos, sob a ótica de Bakhtin, analisar algumas das proposições apresentadas pelo autor com vistas a permitir ao leitor uma maior compreensão do dialogismo bakhtiniano e a forma como este opera na formação do discurso iurdiano. Outrossim, ao nos referirmos aos gêneros do discurso, pretendemos, a partir deste, tentar delimitar a forma como são constituídas as "fronteiras fluídas e porosas" do discurso iurdiano a que se referem Birman e Oro, para, em seguida, desvelarmos a forma como este dialogismo é operacionalizado na construção enunciativa iurdiana através da ressemantização/ressignificação de signos trazidos de outras formações discursivas existentes no universo religioso brasileiro.

\section{BAKHTIN E OS INTERLOCUTORES}

Bakhtin considera o dialogismo como um princípio constitutivo da linguagem e condição sine qua non para a interpretação do sentido contido nas mais diferentes formações discursivas. Para ele, o discurso não é individual porque se constrói no processo comunicativo, e exige pelo menos dois interlocutores, os quais podem ou não ser contemporâneos, ou seja, viver num mesmo momento discursivo.

1 Departamento de Ensino e Currículo/Faced/UFRGS. 
Do ponto de vista sociológico, tais interlocutores são seres sociais que manifestam indiretamente outros discursos relacionados ao contexto social do qual fazem parte e com o qual interagem. Sendo assim, tais formaçôes discursivas manifestadas pelo interlocutor-sujeito seriam sociais e não individuais, como preconizam outros autores. Sob a ótica bakhtiniana, essas manifestações discursivas seriam, ao mesmo tempo, resultado da interação entre os interlocutores-sujeitos e da relação que estes estabelecem com a sociedade, enquanto um todo mais abrangente.

Quando Bakhtin se refere ao diálogo entre tais interlocutores na obra "Marxismo e Filosofia da Linguagem", ele coloca-os no campo da interdiscursividade e da arbitrariedade de sentido de que poderia estar dotado um signo, se não levássemos em conta o contexto no qual este é operacionalizado e o sentido que este adquire em tal sistema de significação. Neste sentido, o próprio autor nos lembra que: a interação entre interlocutores é o princípio fundador da própria linguagem; o sentido do tex to e sua significação dependem, fundamentalmente, da relação estabelecida entre os sujeitos e/ou interlocutores que interagem num mesmo campo discursivo; e que os interlocutores são os próprios sujeitos produtores do texto ou do discurso, de modo que estes lhe dão sentido e estão entre os elementos fundantes do próprio sistema linguístico. Passemos então à compreensão das formas como tais formações discursivas são produzidas e/ou emuladas pelos interlocutores-autores que constituem o sistema discursivo religioso neopentecostal iurdiano.

\section{BAKHTIN E A PRODUÇÃO DO DISCURSO VERBAL}

Quando nos referimos ao processo de comunicação verbal e às formações discursivas que emergem das relações que se estabelecem entre os interlocutores, devemos, necessariamente, considerar a forma como estes discursos são produzidos, sobretudo no que se refere aos gêneros do discurso. Nas palavras de Bakhtin, 
"Todas as esferas da atividade humana, por mais variadas que sejam, estão sempre relacionadas com a utilização da língua. [. . .] em forma de enunciados (orais e escritos), concretos e únicos, que emanam dos integrantes duma ou doutra esfera da atividade humana”. (Bakhtin: 1992, p. 279)

Deste modo, todo enunciado refletiria as condições específicas em que este é produzido, marcado, dessa forma, por seu conteúdo temático, composicional e de estilo. Estes três elementos, por si só, constituiriam, então, o enunciado como um todo. E, deste modo, todo enunciado traria, em si, tipos relativamen te estáveis de enunciados que demarcariam as especificidades do contexto em que o enunciado é produzido.

Outrossim, observa-se que tal esfera da atividade humana - expressa no processo comunicativo manifesto - comporta sobre si um repertório de gêneros do discurso que diferencia e aumenta sua amplitude na medida em que se desenvolve e se complexifica a cada interação produzida. Por esta razão, não devemos minimizar a heterogeneidade dos gêneros do discurso. Importa, contudo, que devemos levar em consideração a diferença existente entre o discurso primário e o discurso secundário.

Os gêneros secundários do discurso são, por sua vez, o resultado de um processo comunicativo mais complexo e evoluído e, geralmente, está dotado de conteúdo artístico, científico, ideológico ou sócio-político. Para Bakhtin (1992), em seu processo de formação, estes gêneros secundários do discu rso - no caso, as formaçōes discursivas iurdianas - absorvem e transmutam os gêneros primários do discurso, ou seja, as formações discursivas das religióes afro. Neste último caso, este se constituiria em circunstâncias de um processo de comunicação verbal espontâneo, comumente utilizado pelos praticantes destas religiōes. Assim, a formação discursiva iurdiana seria, grosso modo, o locus de produção de sentido e de constituição do sujeito.

Desta forma, somos obrigados a discordar de Ribeiro (2005), uma vez que, sob a ótica de Bakhtin, a formação discursiva que se opera no Ritual de Libertação e Cura da Igreja Universal do Reino de Deus é muito mais do que um mero simulacro das formaçóes discursivas manifestas no discurso das re- 
ligiões afro, pois, nas palavras de Manguineau (1984), como refere o próprio autor, estaríamos, fundamentalmente, no campo discursivo, de modo que estas formaçôes discursivas estariam em concorrência e teriam por base um embate ou cisão existente no universo discursivo religioso entre o discurso neopentecostal iurdiano e aquele provindo dos "Terreiros" e "Casas de Umbanda”. Não sendo, portanto, um "simulacro" ou "imagem refletida num espelho torto", como defende Ribeiro (2005), com base em Deleuze.

\section{O DIALOGISMO BAKHTINIANO}

\section{E AS FRONTEIRAS FLUÍDAS DE BIRMAN E ORO}

Se para alguns antropólogos, como Patrícia Birman (1996), a relação que se estabelece entre o neopentecostalismo e as religiōes afro-brasileiras é o resultado de um conflito anterior existente entre elas, temos então que esta é entendida como um espaço de interlocução constante que se caracteriza pelo sincretismo, pela redefinição constante das fronteiras estabelecidas, pela busca de inovaçōes e novos "artefatos simbólicos" que permitam uma maior eficácia do ato performático iurdiano em relação ao seu duplo constitutivo.

Para outros, como Oro (1997), este movimento se "constitui em um importante código de diferen ciação" que caracteriza a identidade iurdiana, a qual é construída em contraste a outras expressões religiosas, mostrandose extremamente fluída e porosa. Como conseqüência desta porosidade/ fluidez decorre um processo de re-semantização dos conteúdos advindos de outras religiôes com vistas à construção de significados próprios que são emulados nas práticas iurdianas de libertação e cura, sobretudo, aquelas provenientes dos cultos afro-brasileiros.

E, deste modo, como afirma Ribeiro (2005), há uma inconstância das fronteiras existentes entre o discurso iurdiano e das religiōes afro, que se dá via processo de re-semantização, tal tradução correspondendo a uma formação discursiva relacional que se produziria a partir de seu duplo, sem o qual deixaria de ter sentido. Mas, neste caso, questiona-se: como podemos 
explicitar tais contornos fluidos e porosos que se materializam nos discursos iurdianos constituídos a partir da heterogeneidade existente no seu duplo constitutivo - as religiōes afro?

Dentro de uma perspectiva dialógica, uma possível resposta residiria na forma como os interlocutores interagem e dão sentido às formaçóes discursivas até então dispersas no campo religioso brasileiro. De modo que, é por meio da constante ressignificação das formações discursivas existentes que o discurso iurdiano se constitui enquanto tal. É, então, através de um contexto definido a priori - o ritual de libertação e cura - que estas ganham sentido e significado expressivo para aqueles que se utilizam dessas formaçôes discursivas inerentes ao campo religioso neopentecostal, principalmente na relação hierárquica discursiva que se estabelece entre: bispo-pastor e fiel; bispo e fiel; pastor e fiel; e, bispo e encosto.

Desta forma, o exorcismo presente tanto no ritual de libertação como na sessão de descarrego é tido como um ritual discursivo, como proposto por Côrrea (1989 apud Ribeiro, 2005), e nos remete a uma formação discursiva própria do sistema religioso neopentecostal iurdiano. Sob esta acepção, tanto o bispo como o fiel e o encosto têm seus papéis definidos $a$ priori. De modo que, de outra forma, tal formação discursiva estaria, em termos bakhtinianos, vazia de sentido se extraída do contexto em que ocorre.

Todavia, diferentemente do que se observa à primeira vista, tal sistema simbólico manifesto no ritual iurdiano não é um sistema fechado, pois ele dialoga intermitantemente com o seu duplo constituído, ressignificando a cada instante suas práticas discursivas e rituais. Assim, seria esse conjunto de enunciados e comportamentos evocados nas formaçõ es discursivas iurdianas que garantiriam eficácia de tais práticas, pois, com evocação do Espírito Santo pelo bispo-pastor, este garantiria para si o poder de coerção e controle das ações do fiel e do encosto - não permitindo a estes ${ }^{2}$ o direito da ação. Outrossim, cabe apenas ao fiel e ao encosto, avalizar as formaçōes discursivas do proferiente (bispo-pastor) que tem seu poder legitimado na evocação anterior dos poderes concedidos a ele pelo Espírito Santo.

2 O "fiel" e o "Encosto". 
Contudo, de nada valeria tal legitimidade trazida pela evocação do Espírito Santo se seus interlocutores não a acedessem como dotada de sentido. Este sentido, expresso na autoridade discursiva do bispo-pastor, é conseqüência da relação que este estabel ece com as diferentes formaçõ es discursivas que compóem o sistema de crenças iurdiano, de modo que o bispo-pastor, em sua posição de sujeito ativo dentro do sistema simbólico iurdiano, é quem define aquilo que pode e deve se dito (Pêcheux, 1995). Tal formação discursiva é, portanto, o locus privilegiado de formação do sujeito.

Assim, não se pode negar de forma alguma a existência de seu duplo os cultos afro - visto que sem estes suas práticas discursivas e rituais tornarse-iam vazias de sentido. Portanto, a partir de tal pressuposto podemos constatar que os limites da formação discursiva iurdiana residem nas práticas religiosas das religióes afro-brasileiras, pois sem o conhecimento de tais práticas seria difícil a Igreja Universal do Reino de Deus constituir-se enquanto tal, em um sistema simbólico válido e dotado de sentido no "mercado religioso neopentecostal". Cabe também lembrar que é essa fluidez e porosidade a que se referem Oro e Birman que garante à IURD a manutenção de seu "rebanho".

\section{A OPERACIONALIZAÇÃO DO DIALOGISMO BACKTINIANO E A MANUTENÇÃO DAS FRONTEIRAS DISCURSIVAS ATRAVÉS DA CONSTRUÇÃO ENUNCIATIVA IURDIANA E A MANIPULAÇÃO DOS SIGNOS RELIGIOSOS}

Mais do que simplesmente emular os signos das religiōes afro, num pretenso simulacro que se constrói pela diferenciação discursiva, o discurso iurdiano dá a estes signos uma natureza própria, manifesta no discurso imanente do bispo-pastor, e que é validado pelo sujeito-fiel no momento da celebração e culto ao Espírito Santo. Com base nisto, operacionaliza-se no "Ritual de Libertação e Cura" iurdiano uma reinterpretação das formações discursivas das religiōes afro-brasileiras que têm seu significado extir- 
pado do sentido contido em suas formações espontâneas captadas nos "Terreiros" e "Casas de Umbanda".

Este signo, agora livre do contexto em que surgiu e da tematização dada pela interação entre os interlocutores que primeiramente dele se utilizaram, é, então, reintroduzido no discurso religioso iurdiano onde seu sentido é ressignificado com vistas a adequá-lo às necessidades impostas de se lidar com a dicotomia bem $/ \mathrm{mal}^{3}$, tão presente na formação discursiva iurdiana. Sob esta lógica estaria reservado aos signos trazidos dos cultos afro, como por exemplo, o "Exu", o "Encosto", os "Orixás", o "Preto-Velho" etc., as atribuiçôes relativas a entidades malignas que, necessariamente, só poderiam ser controladas ou expurgadas daqueles que procuram o "Ritual de Libertação e Cura" com a intervenção do Espírito Santo.

Desta forma, é através do dialogismo a que se refere Bakhtin que o campo discursivo iurdianoé construído, uma vez que é por meio da oposição entre estados imanentes - que pendem para o bem ou para o mal - que se dá o alargamento das fronteiras discursivas que perpassam o referido discurso. Este, por sua vez, está em constante construção, sendo revisto e ressignificado em cada momento da celebração realizado nas catedrais da fé, ou nos templos iurdianos. Outrossim, dada a dinamicidade e a rapidez com que o discurso iurdiano se transmuta a partir de informações trazidas pelos sujeitos-fiéis, têm-se que cada momento de celebração é único no tempo e no espaço, tendo, este, seus próprios receptáculos e repertórios de análise.

Cada Catedral da Fé estaria assim dotada do mesmo panteão de entidades e signos acionados pelo Ritual de Libertação e Cura; contudo, a forma como este é operacional izado seria dada pelo interdiscurso do bispo-pastor com sua clientela, de modo que se em um de seus templos em

\footnotetext{
3 Tal dicotomia estaria presente na formação discursiva iurdiana espontânea onde se operacionaliza a construção de que "Eu era assim (destaque ao aspecto negativo, ao mal espiritual, etc.)... depois que comecei a frequentar a Igreja Universal do Reino de Deus, minha vida mudou, e hoje eu sou ... (destaque ao aspecto positivo, ao bem espiritual trazido pela IURD, ao renascimento no Espírito Santo).
} 
Porto Alegre os males espirituais como a depressão, a vontade de se matar, entre outros, são atribuídos à um Exu X, em outro templo da mesma cidade, dado o contexto da comunidade em que este está inserido, este seria a entidade responsável pelos problemas financei ros que afligiriam os frequentadores do outro templo.

Disto conclui-se que, para além da idéia de um mero simulacro da alteridade, o discurso iurdiano seria ele próprio o seu elemento constituinte, atribuindo sentidos e formas de percepção da realidade que lhe são únicas, e que impregnam de sentido signos trazidos de fora do campo discursivo neopentecostal, sendo estes ressignificados a partir do sistema simbólico iurdiano, os quais se tornam dotados de sentido e se integram a ele, quando passam a fazer parte da dicotomia operada pela Igreja Universal do Reino de Deus en tre as "coisas do bem" e as "coisas do mal".

Da mesma forma, longe está querermos diminuir a contribuição do estudo de Ribeiro (2005) para a análise do discurso religioso iurdiano. Contudo, tentamos, a partir de uma análise crítica de algumas proposições apresentadas pelo autor, deixar evidente que tais formações discursivas referendadas (FD1 e FD2) são, em si, construçôes discursivas tributárias a diferentes concepções religiosas e servem como mote para validação de seu sentido contido e imanente tanto no campo religioso neopentecostal quanto afro-brasileiro.

Todavia, no momento em que os signos evocados por FD1 são trazidos para dentro da Sessão de Descarrego pelo bispo-pastor, esses se tornam manifestações discursivas concretas, deixando de ser um mero simulacro, e adquirindo, assim, sua materialidade discursiva no que se poderia denominar de uma FD de segunda ordem em relação à FD1, não dependendo mais dos conteúdos contidos em FD2, visto que estes são estirpados de sua significação original quando passam a compor o discurso iurdiano. 


\section{REFERÊNCIAS}

BAKHTIN, Mikhail. Estética da criação verbal. São Paulo, Martins Fontes, 1992.

BAKHTIN, Mikhail. Marxismo e Filosofia da Linguagem. São Paulo, Hucitec, 1995.

BIRMAN, Patricia. Cultos de possessão e pentecostalismo no Brasil: passagens. Religião e Sociedade, v. 17, n.1-2. Pentecostes e nova Era: fronteiras, passagens. Rio de Janeiro, ISER. MAINGUINEAU, Dominique. Genèses du discours. Bruxelas, Pierre Mardaga, 1984.

ORO, Ari Pedro. "Neopentecostais e afro-brasileiros: quem gan hará esta guerra?" Debates do NER - UFRGS. Ano 1, 1997, n. 1, pp. 10-36.

PÊCHEUX, Michel. Semântica e discurso : uma crítica à afirmação do óbvio. 2.ed. Campinas, Ed. da UNICAMP, 1995.

RIBEIRO, Jaçanã. O simulacro da alteridade: uma análise discursiva do ritual de exorcismo da Igreja Universal do Reino de Deus. In: Debates do NER - UFRGS. Ano 6, 2005, n. 7. 
